\title{
XANES and XPS Study on Microstructure of Mn-Doped ZnO Films
}

\author{
B. Zhang ${ }^{1,2}$, M. Li ${ }^{1,2}$, J. Z. Wang ${ }^{1,2}$, L. Q. Shi ${ }^{1,2}$, H. S. Cheng ${ }^{1,2}$ \\ ${ }^{1}$ Applied Ion Beam Physics Laboratory (Key Laboratory of the Ministry of Education), Institute of Modern Physics, Fudan University, \\ Shanghai, China; ${ }^{2}$ Department of Nuclear Science and Technology, Fudan University, Shanghai, China. \\ Email: binzhang@fudan.edu.cn
}

Received January $24^{\text {th }}, 2013$; revised March 27 ${ }^{\text {th }}, 2013$; accepted April $11^{\text {th }}, 2013$

Copyright (C) 2013 B. Zhang et al. This is an open access article distributed under the Creative Commons Attribution License, which permits unrestricted use, distribution, and reproduction in any medium, provided the original work is properly cited.

\begin{abstract}
Microstructure of $\mathrm{ZnO}: \mathrm{Mn}$ films with various $\mathrm{Mn}$ concentration was investigated with XANES and XPS. The experimental results revealed a substitution of $\mathrm{Mn}$ in $\mathrm{ZnO}$ and also excluded the existence of Mn oxides or metallic manganese clusters. The substitutional Mn presented a divalent state and all the $\mathrm{ZnO}: \mathrm{Mn}$ films were n-type. Room temperature ferromagnetism monotonously decreases with the decrease of the electron carrier concentration. The observed ferromagnetism should come from the carrier-mediated exchange.
\end{abstract}

Keywords: ZnO-Based DMS; Mn Substitution; XANES; XPS

\section{Introduction}

Recently, diluted magnetic semiconductors (DMSs) [1-3] have attracted much interest for their potential applications in spintronics. Among them, Mn-doped $\mathrm{ZnO}$ is the most favorable candidate because the $\mathrm{Mn}$ ion possesses the highest magnetic moment among $3 \mathrm{~d}$ transition metals and can create a fully polarized stable state due to halffilled $3 \mathrm{~d}$ bands. There are many reports on room temperature ferromagnetism (RTFM) in the system since the theoretical prediction of RTFM by Dietl et al. in 2000 [4]. However, the origin of ferromagnetism (FM) is still unclear. Some studies indicate that FM might come from the precipitates (e.g., clusters and/or a secondary phase) [5-7]. On the other hand, some studies think that FM might originate from exchange interactions between the localized magnetic moment of the substitutional ions on $\mathrm{Zn}$ sites and free charge carriers generated by doping [8-10]. Another origin of FM might be defect-mediated coupling of spins [11-13]. In Mn-doped $\mathrm{ZnO}$, the defects are mainly oxygen/zinc vacancies or interstitials. The defect like $\mathrm{O}$ vacancies or $\mathrm{Zn}$ interstitials might trap an electron, forming an $\mathrm{H}$-like structure. These electrons confined in $\mathrm{O}$ vacancies or $\mathrm{Zn}$ interstitials would interact with the delectrons of a $\mathrm{Mn}$ atom within their orbits, yielding a bound magnetic polaron (BMP) [14]. The BMPs overlap with each other and hence inducing FM. Recently, FM is also observed in n-type $\mathrm{ZnO}: \mathrm{Mn}$ films at or above RT, and the magnetization monotonously depends on the electron carrier concentration $[15,16]$. The experimental result contradicts the theoretical prediction which requires a high concentration of holes for FM [4,17]. Therefore, to further investigate and clarify the origin of FM, it is very important to investigate microstructrure of Mn doped $\mathrm{ZnO}$, especially occupation sites and valent states of $\mathrm{Mn}$ atoms.

X-ray absorption near-edge structure (XANES) spectroscopy is a powerful probe for providing a "fingerprint" of chemical states and local electronic structure of incorporated atoms in the host compounds even in a dilute concentration. In particular, the absolute energy position of the edge spectra contains information about the valence state of the absorbing elements. In this paper we employ XANES combining other analysis techniques to investigate the Mn local atomic and electronic structures as well as magnetic interactions in $\mathrm{Mn}$-doped $\mathrm{ZnO}$ film.

\section{Experimental}

Mn-doped $\mathrm{ZnO}$ films were deposited on (0001) sapphire substrates (99.999\%) by radio frequency (RF) magnetron sputtering, with a composite target of $\mathrm{ZnO}(99.99 \%)$ and Mn (99.99\%). According to the area ratio of $\mathrm{ZnO}$ and $\mathrm{Mn}$, the Mn-doped content could be adjusted. High purity $\operatorname{Ar}(99.999 \%)$ was introduced into the sputtering chamber at the base pressure of $\leq 6.0 \times 10^{-4} \mathrm{~Pa}$. The Ar- 
flow rate was 20 SCCM (SCCM denotes cubic centimeter per minute at STP (standard temperature and pressure)). The working pressure was $0.5 \mathrm{~Pa}$, the sputtering power $90 \mathrm{~W}$ and the substrate temperature $500^{\circ} \mathrm{C}$. Prior to a deposition, a pre-sputtering cleaning was performed for about 20 minutes to eliminate possible contaminants from the target surface.

The Mn K-edge XANES $(6.539 \mathrm{keV})$ spectra were measured at the U7C beamline of National Synchrotron Radiation Laboratory of China. High resolution XPS spectra were detected using a Kratos AXIS Ultra DLD spectrometer with a high resolution of $0.48 \mathrm{eV}$. The monochromatic $\mathrm{Al} \mathrm{K} \alpha \mathrm{X}$-ray $(\lambda=0.8339 \mathrm{~nm})$ was used as the incident light. The binding energy scale was calibrated using the $\mathrm{C} 1 \mathrm{~s}$ line at $284.8 \mathrm{eV}$. Electrical properties were carried out at room temperature by Hall effect measurements using a Van der Pauw four-point method. An In electrode was made by soldering indium at four corns of the sample surface. The linear I-V behavior for all samples indicated a good Ohmic contact between In electrode and film layer. The magnetic property at room temperature was measured by the Quantum Design MPMSXL7 SQUID magnetometer.

\section{Results and Discussion}

To detect Mn cluster and any secondary phases in the ZnO:Mn samples, we have measured Mn K-edge XANES of all the DMS samples and Mn metal. For clarity, Figure 1 only shows the measured spectra of the $\mathrm{Zn}_{0.89} \mathrm{Mn}_{0.11} \mathrm{O}$ film and Mn metal. The FEFF 9.0 [18] simulations of $\mathrm{Mn}$ oxides $\left(\mathrm{MnO}, \mathrm{MnO}_{2}, \mathrm{Mn}_{2} \mathrm{O}_{3}, \mathrm{Mn}_{3} \mathrm{O}_{4}\right)$ are also shown in Figure 1. The spectrum of the DMS sample is quite different from Mn oxides and metallic $\mathrm{Mn}$. The spectrum of $\mathrm{MnO}$ has the same features as that of the DMS film in a high energy region (Peak B, C and $\mathrm{D})$, while there is no agreement in the low energy region

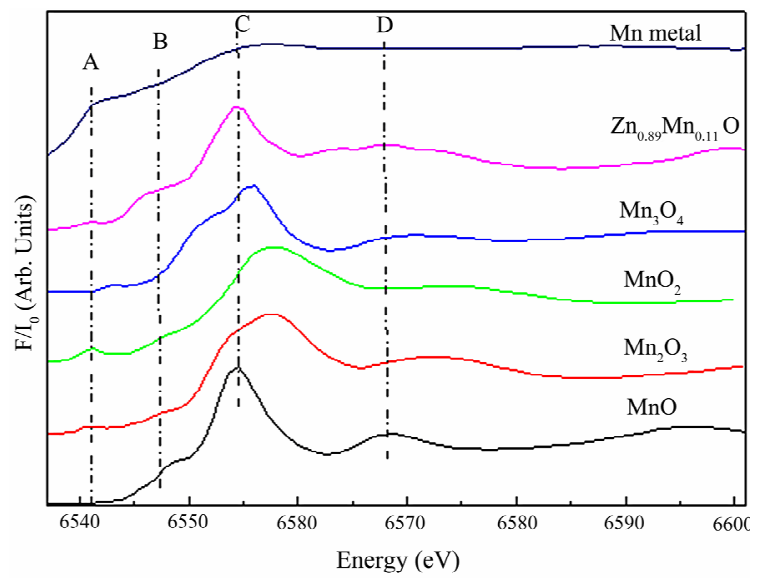

Figure 1. Mn K-edge experimental XANES spectra for the $\mathrm{Zn}_{0.89} \mathrm{Mn}_{0.11} \mathrm{O}$ film and $\mathrm{Mn}$ metal, and $\mathrm{Mn}$ K-edge calculated XANES spectra for $\mathrm{MnO}, \mathrm{MnO}_{2}, \mathrm{Mn}_{2} \mathrm{O}_{3}$ and $\mathrm{Mn}_{3} \mathrm{O}_{4}$.
(Peak A). It implies that there are no Mn oxides or metallic manganese clusters in the films. The same results have been obtained using an extended X-ray absorption fine structure (EXAFS) and synchrotron radiation X-ray diffraction (SR-XRD) [19]. Additionally, the Mn absorption edge position of the DMS samples is close to that of $\mathrm{MnO}$, suggesting the existence of $\mathrm{Mn}^{2+}$.

In order to further investigate Mn occupation sites, we have attempted to perform XANES calculations with the FDMNES 2007 code [20] at Mn K-edge for a lot of possible configurations such as the substitutional $\mathrm{Mn}_{\mathrm{Zn}}$, the interstitial $\mathrm{Mn}_{\mathrm{I}}$, the $\mathrm{Mn}_{\mathrm{Zn}}-\mathrm{Mn}_{\mathrm{I}}$ dimer, and the $\mathrm{Mn}_{\mathrm{Zn}} \mathrm{O}-$ $\mathrm{Mn}_{\mathrm{Zn}}$. For the interstitial $\mathrm{Mn}_{\mathrm{I}}$ model, $\mathrm{Mn}$ is placed at the void in wurtzite $\mathrm{ZnO}$ structure locating at the center of the $\mathrm{Zn}$ tetrahedron. The $\mathrm{Mn}_{\mathrm{Zn}}-\mathrm{Mn}_{\mathrm{I}}$ dimer is based on the interstitial structure, where one $\mathrm{Zn}$ atom of the Mn-containing tetrahedron is substituted by a Mn atom. For the $\mathrm{Mn}_{\mathrm{Zn}}-\mathrm{O}-\mathrm{Mn}_{\mathrm{Zn}}$, two subtitutional $\mathrm{Mn}$ atoms on $\mathrm{Zn}$ sites are separated by an $\mathrm{O}$ atom. All XANES functions are calculated within a sphere of $6 \AA$ radius, whose center is the absorber atom Mn. Figure 2 shows the spectra of the DMS samples and the calculated spectra from the above-mentioned models. Obviously, the spectra of the DMS samples are different from that of the interstitial $\mathrm{Mn}_{\mathrm{I}}$, which means that $\mathrm{Mn}$ could not exist at the interstitial site. We also explore the clustering tendency of the $\mathrm{Mn}$ atoms in $\mathrm{ZnO}$. From the obvious difference between the spectra of the $\mathrm{Mn}_{\mathrm{Zn}}-\mathrm{Mn}_{\mathrm{I}}$ dimer, the $\mathrm{Mn}_{\mathrm{Zn}}-\mathrm{O}-\mathrm{Mn}_{\mathrm{Zn}}$ and the DMS samples, we can exclude the phenomena. In the XANES spectra of the DMS samples, there are four characteristic peaks A $(6541 \mathrm{eV}), \mathrm{B}(6546 \mathrm{eV}), \mathrm{C}(6555$ $\mathrm{eV})$ and $\mathrm{D}(6567 \mathrm{eV})$. The preedge peak $\mathrm{A}$ can be interpreted as the transition of Mn 1s core electron to the unoccupied Mn 3d and O 2p hybridized states. In the sub stitutional model, " $\mathrm{Mn}_{\mathrm{Zn}}$ " represent the model of no op-

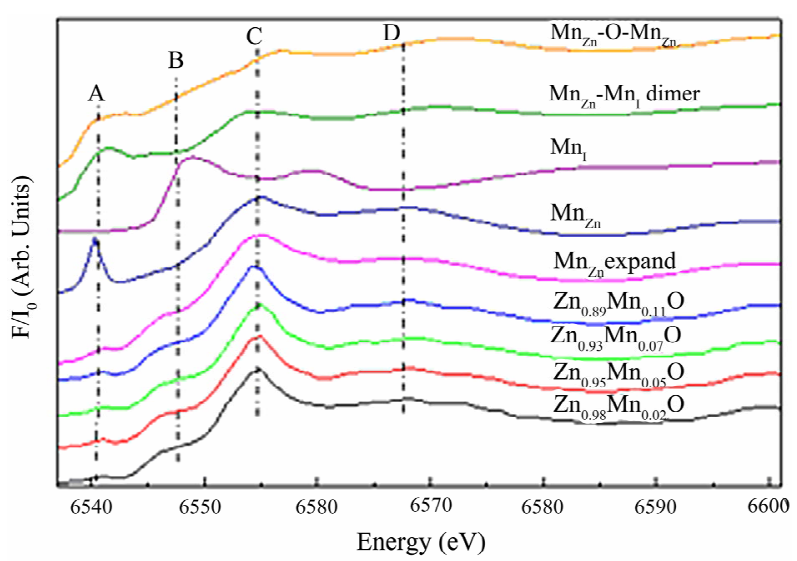

Figure 2. Mn K-edge experimental XANES spectra for the $\mathrm{Zn}_{1-\mathrm{x}} \mathrm{Mn}_{\mathrm{x}} \mathrm{O}$ films and Mn K-edge calculated XANES spectra for different $\mathrm{Mn}$ occupation sites in wurtzite $\mathrm{ZnO}$ lattice: substitutional $M n_{Z n}$, interstitial $M n_{I}, M n_{Z n}-M n_{I}$ dimer, and $\mathrm{Mn}_{\mathrm{Zn}}-\mathrm{O}-\mathrm{Mn}_{\mathrm{Zn}}$. 
timizing the geometry of the studied configurations, i.e., the bond lengths of $\mathrm{Mn}_{\mathrm{Zn}}-\mathrm{O}$ and $\mathrm{Mn}_{\mathrm{Zn}}-\mathrm{Zn}$ is 1.97 and $3.20 \AA$, respectively, while " $\mathrm{Mn}_{\mathrm{Zn}}$ expand" represent the model in which the bond lengths of $\mathrm{Mn}_{\mathrm{Zn}}-\mathrm{O}$ and $\mathrm{Mn}_{\mathrm{Zn}}-\mathrm{Zn}$ is expanded to 2.03 and $3.28 \AA$, respectively. In the $\mathrm{Mn}_{\mathrm{Zn}}$ model, A, C and D peaks can be well reproduced except the $\mathrm{B}$ peak. On the other hand, the height of the Peak A in the $\mathrm{Mn}_{\mathrm{Zn}}$ model is much larger than that in the DMS samples. However, in the $\mathrm{Mn}_{\mathrm{Zn}}$ expand model, four characteristic peaks can be well reproduced and the calculated spectrum resembles those of the DMS samples. It implies that $\mathrm{Mn}$ atoms are incorporated into the $\mathrm{ZnO}$ crystal lattice by the substitution on $\mathrm{Zn}$ sites, accompanying with an expansion of the $\mathrm{Mn}_{\mathrm{Zn}}-\mathrm{O}$ and $\mathrm{Mn}_{\mathrm{Zn}}-\mathrm{Zn}$ bond lengths due to the larger atomic radius of $\mathrm{Mn}$ compared with $\mathrm{Zn}$. The same results have been observed by an extended X-ray absorption fine structure (EXAFS) [19].

The valent state of Mn in the DMS films is detected by high resolution XPS. In Figure 3, the Mn $2 p_{3 / 2}$ peak for the DMS samples is located at $640.73 \mathrm{eV}$, which is very close to $\mathrm{Mn}^{2+}$ in $\mathrm{MnO}\left(\mathrm{Mn} \mathrm{2} \mathrm{p}_{3 / 2}: 640.7 \mathrm{eV}\right)$ according to the XPS handbook. It well agrees with those reported in the literature, indicating a divalent state of the Mn ions in $\mathrm{ZnO}: \mathrm{Mn}$ films [21,22]. Moreover, from the XPS handbook we also know that the Mn $2 \mathrm{p}_{3 / 2}$ peaks for metallic $\mathrm{Mn}, \mathrm{Mn}_{3} \mathrm{O}_{4}, \mathrm{Mn}_{2} \mathrm{O}_{3}$ and $\mathrm{MnO}_{2}$ are located at 639, 641.2, 641.6 and $642.2 \mathrm{eV}$, respectively. So we can exclude the existence of Mn oxides or metallic manganese clusters in the films, in good agreement with the XANES analysis.

Figure 4 shows the magnetization curves at room temperature. These magnetization curves are obtained with the applied field parallel to the plane of the sample. The diamagnetic background of $\mathrm{ZnO}$ and sapphire substrate are subtracted. The hysteresis loops show the clear ferromagnetic behavior of these $\mathrm{Mn}$-doped $\mathrm{ZnO}$ films at room temperature. From Figure 4, the saturation mag-

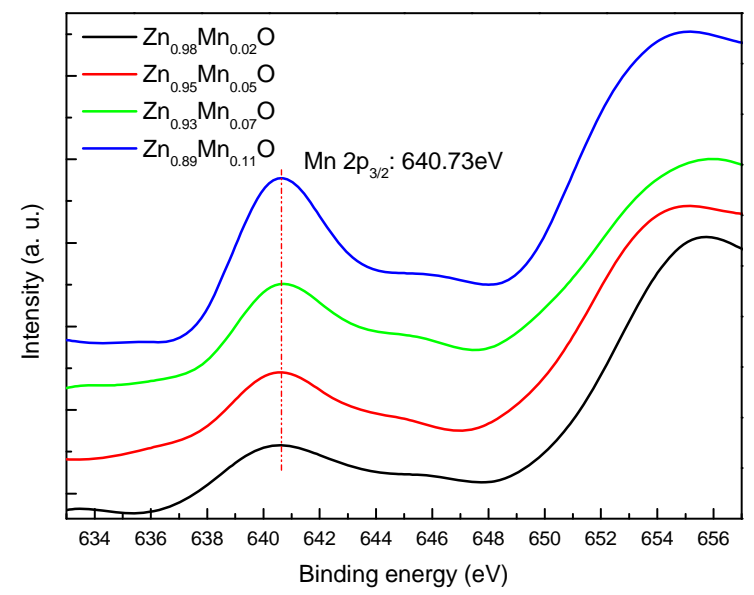

Figure 3. The high resolution XPS Mn-2p spectra for the $\mathrm{Zn}_{1-\mathrm{x}} \mathrm{Mn}_{\mathrm{x}} \mathrm{O}$ films. netic moment (Ms) first decreases as Mn content increases from 2 to $7 \mathrm{at} \%$, and then remain at $\mathrm{Mn}$ content from 7 to $11 \mathrm{at} \%$.

Hall effect was used to detect the carrier type and concentration of these $\mathrm{Mn}$-doped $\mathrm{ZnO}$ films. The results show that all the Mn-doped $\mathrm{ZnO}$ films are n-type. For the 2 at $\%$ Mn doping, the carrier concentration (n) and the saturation magnetic moment (Ms) are $2.86 \times 10^{18} \mathrm{~cm}^{-3}$ and $0.083 \mu_{\mathrm{B}} / \mathrm{Mn}$, respectively, while for $5 \mathrm{at} \%$, $\mathrm{n}$ and $\mathrm{Ms}$ are $3 \times 10^{17} \mathrm{~cm}^{-3}$ and $0.016 \mu_{\mathrm{B}} / \mathrm{Mn}$, respectively. The values of $\mathrm{n}$ and $\mathrm{Ms}\left(\mathrm{n}: 1 \times 10^{17} \mathrm{~cm}^{-3}, \mathrm{Ms}: 0.015 \mu_{\mathrm{B}} / \mathrm{Mn}\right)$ for $7 \mathrm{at} \%$ are the same as that for 11 at $\%$. From Figure 5, ferromagnetism monotonously decreases with the decrease of the electron carrier concentration, in good agreement with the results in Refs. $[15,16]$. According to the Zener model [4], which explains the exchange interaction between the magnetic impurity atoms in the DMS as mediated by free charge carrier, the increase in charge carrier concentration can enhance the magnetic or-

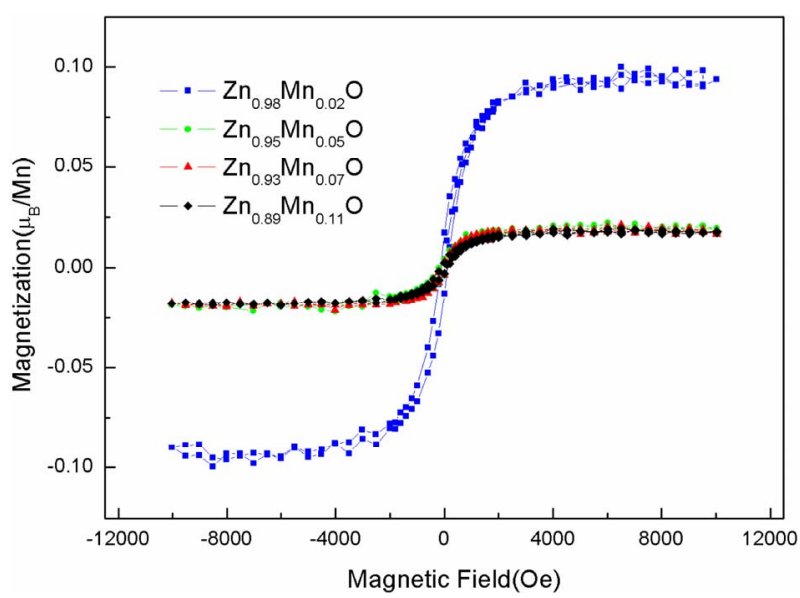

Figure 4. Hysteresis loops for the $\mathrm{Zn}_{1-\mathrm{x}} \mathrm{Mn}_{\mathrm{x}} \mathrm{O}$ films.

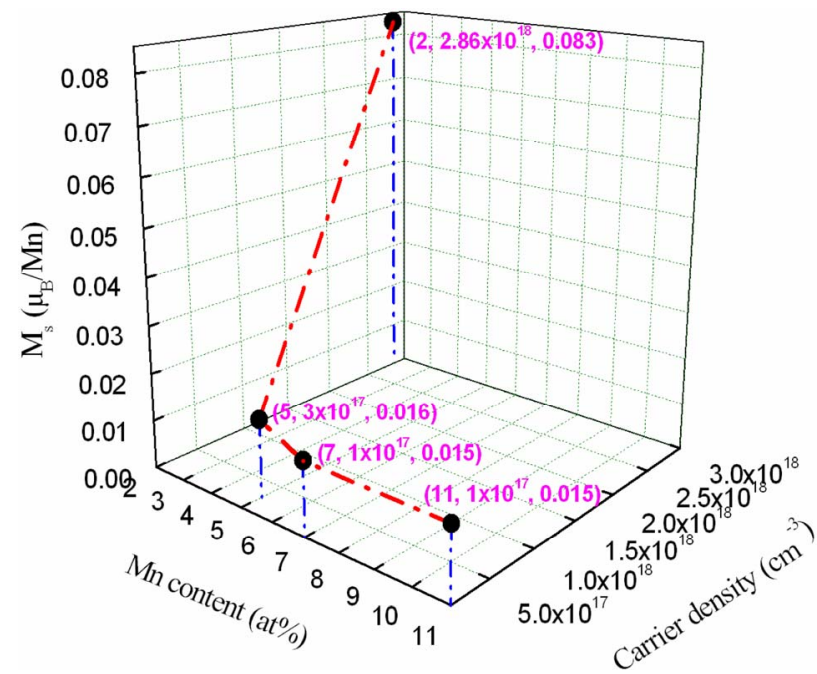

Figure 5. Ms as a function between Mn concentration and carrier density for the $\mathrm{Zn}_{1-\mathrm{x}} \mathrm{Mn}_{\mathrm{x}} \mathrm{O}$ films. 
dering. Therefore, we deduce that our observed ferromagnetism should come from the carrier-mediated exchange.

\section{Conclusion}

$\mathrm{ZnO}$ films doped with different $\mathrm{Mn}$ concentration were deposited on sapphire substrates by RF magnetron sputtering. The measurements revealed a substitution of $\mathrm{Mn}$ in $\mathrm{ZnO}$ and also excluded the existence of $\mathrm{Mn}$ oxides or metallic manganese clusters. The substitutional Mn presented a divalent state and all the $\mathrm{ZnO}: \mathrm{Mn}$ films were n-type. Room temperature ferromagnetism monotonously decreases with the decrease of the electron carrier concentration. The observed ferromagnetism should come from the carrier-mediated exchange.

\section{Acknowledgements}

This work is supported by the National Natural Science Foundation of China (Grant Nos. 10775033 and 11075038). The authors would like to thank the U7C beam line of National Synchrotron Radiation Laboratory of China for providing the beam time.

\section{REFERENCES}

[1] B. Zhang, Q. H. Li, L. Q. Shi, H. S. Cheng and J. Z. Wang, "Room Temperature Ferromagnetism of Fe-Implanted ZnO Film," Journal of Vacuum Science \& Technology A, Vol. 26, No. 6, 2008, pp. 1469-1473. doi:10.1116/1.2990855

[2] B. Zhang, L. Q. Shi, C. C. Chen and D. G. Zhao, "PIXE Analysis of Fe Content in Fe-Implanted GaN Film," Nuclear Instruments and Methods in Physics Research Section B, Vol. 252, No. 2, 2006, pp. 225-229. doi:10.1016/j.nimb.2006.09.007

[3] X. F. Wang, J. B. Xu, W. Y. Cheng, J. An and N. Ke, "Aggregation-Based Growth and Magnetic Properties of Inhomogeneous Cu-Doped ZnO Nanocrystals," Applied Physics Letters, Vol. 90, No. 21, 2007, Article ID: 212502. doi:10.1063/1.2741408

[4] T. Dietl, H. Ohno, F. Matsukura, J. Cibert and D. Ferrand, "Zener Model Description of Ferromagnetism in ZincBlende Magnetic Semiconductors," Science, Vol. 287, No. 5455, 2000, pp. 1019-1022. doi:10.1126/science.287.5455.1019

[5] A. C. Tuan, J. D. Bryan, A. B. Pakhomov, V. Shutthanandan, S. Thevuthasan, D. E. McCready, D. Gaspar, M. H. Engelhard, J. W. Rogers Jr., K. Krishnan, D. R. Gamelin and S. A. Chambers, "Epitaxial Growth and Properties of Cobalt-Doped $\mathrm{ZnO}$ on $\alpha-\mathrm{Al}_{2} \mathrm{O}_{3}$ Single-Crystal Substrates," Physical Review B, Vol. 70, No. 5, 2004, Article ID: 054424. doi:10.1103/PhysRevB.70.054424

[6] X. Z. Li, J. Zhang and D. J. Sellmyer, "Structural Study of Mn-Doped ZnO Films by TEM," Solid State Communications, Vol. 141, No. 7, 2007, pp. 398-401. doi:10.1016/j.ssc.2006.11.022

[7] K. Potzger, S. Q. Zhou, H. Reuther, A. Mücklich, F.
Eichhorn, N. Schell, W. Skorupa, M. Helm, J. Fassbender, T. Herrmannsdörfer and T. P. Papageorgiou, "Fe Implanted Ferromagnetic ZnO," Applied Physics Letters, Vol. 88, No. 5, 2006, Article ID: 052508.

doi:10.1063/1.2169912

[8] C. Yang, B. Zhang, J. Z. Wang, L. Q. Shi, H. S. Cheng, T. Y. Yang, W. Wen and F. C. Hu, "Microstructure and Room Temperature Ferromagnetism of $\mathrm{Cu}$-Doped $\mathrm{ZnO}$ Films," Nuclear Instruments and Methods in Physics, Vol. 283, 2012, pp. 24-28. doi:10.1016/j.nimb.2012.04.007

[9] C. Yang, B. Zhang, J. Z. Wang, L. Q. Shi, H. S. Cheng, T. Y. Yang, W. Wen and F. C. Hu, "EXAFS and SR-XRD Study on $\mathrm{Cu}$ Occupation Sites in $\mathrm{Zn}_{1-\mathrm{x}} \mathrm{Cu}_{\mathrm{x}} \mathrm{O}$ Diluted Magnetic Semiconductors," Nuclear Science and Techniques, Vol. 23, 2012, pp. 65-69.

[10] X. J. Liu, X. Y. Zhu, C. Song, F. Zeng and F. Pan, "Intrinsic and Extrinsic Origins of Room Temperature Ferromagnetism in Ni-Doped ZnO Films," Journal of Physics D: Applied Physics, Vol. 42, 2009, Article ID: 035004. doi:10.1088/0022-3727/42/3/035004

[11] D. Gao, Z. Zhang, J. Fu, Y. Xu, J. Qi and D. Xue, "Room Temperature Ferromagnetism of Pure ZnO Nanoparticles," Journal of Applied Physics, Vol. 105, No. 11, 2009, Article ID: 113928 . doi:10.1063/1.3143103

[12] S. Banerjee, M. Mandal, N. Gayathri and M. Sardar, "Enhancement of Ferromagnetism upon Thermal Annealing in Pure ZnO," Applied Physics Letters, Vol. 91, No. 18, 2007, Article ID: 182501. doi:10.1063/1.2804081

[13] X. G. Chen, Y. B. Yang, R. Wu, R. Liu, X. D. Kong, L. Han, Y. C. Yang and J. B. Yang, "Room Temperature Magnetic Properties of ZnO Nanostructured Films," Physica B, Vol. 406, No. 6, 2011, pp. 1341-1344. doi:10.1016/j.physb.2011.01.030

[14] J. M. D. Coey, M. Venkatesan and C. B. Fitzgerald, "Donor Impurity Band Exchange in Dilute Ferromagnetic Oxides," Nature Materials, Vol. 4, No. 2, 2005, pp. 173179. doi: $10.1038 /$ nmat1310

[15] Z. Yang, J. L. Liu, M. Biasini and W. P. Beyermann, "Electron Concentration Dependent Magnetization and Magnetic Anisotropy in ZnO:Mn Thin Films," Applied Physics Letters, Vol. 92, No. 4, 2008, Article ID: 042111. doi:10.1063/1.2838753

[16] M. Ivill, S. J. Pearton, Y. W. Heo, J. Kelly, A. F. Hebard and D. P. Norton, "Magnetization Dependence on Carrier Doping in Epitaxial $\mathrm{ZnO}$ Thin Films Co-Doped with $\mathrm{Mn}$ and P," Journal of Applied Physics, Vol. 101, No. 12, 2007, Article ID: 123909. doi:10.1063/1.2739302

[17] K. Sato and H. Katayama-Yoshida, "Material Design for Transparent Ferromagnets with ZnO-Based Magnetic Semiconductors," Japanese Journal of Applied Physics Part 2, Vol. 39, 2000, pp. L555-L558. doi:10.1143/JJAP.39.L555

[18] A. L. Ankudinov, B. Ravel, J. J. Rehr and S. D. Conradson, "Real-Space Multiple-Scattering Calculation and Interpretation of x-Ray-Absorption Near-Edge Structure," Physical Review B, Vol. 58, No. 12, 1998, pp. 7565-7576. doi:10.1103/PhysRevB.58.7565

[19] M. Li, B. Zhang, J. Z. Wang, L. Q. Shi, H. S. Cheng, Y. Z. Wang, H. Y. Lv, T. Y. Yang, W. Wen and F. C. Hu, 
"EXAFS and SR-XRD Study on Mn Occupations in $\mathrm{Zn}_{1-\mathrm{x}} \mathrm{Mn}_{\mathrm{x}} \mathrm{O}$ Diluted Magnetic Semiconductors," Nuclear Instruments and Methods in Physics Research Section B, Vol. 269, No. 21, 2011, pp. 2610-2613. doi:10.1016/j.nimb.2011.07.094

[20] Y. Joly, "X-Ray Absorption Near-Edge Structure Calculations beyond the Muffin-Tin Approximation," Physical Review B, Vol. 63, No. 12, 2001, Article ID: 125120. doi:10.1103/PhysRevB.63.125120

[21] H. Y. Xu, Y. C. Liu, C. S. Xu, Y. X. Liu, C. L. Shao and
R. Mu, "Room-Temperature Ferromagnetism in (Mn, N)Codoped ZnO Thin Films Prepared by Reactive Magnetron Cosputtering," Applied Physics Letters, Vol. 88, No. 24, 2006, Article ID: 242502. doi:10.1063/1.2213929

[22] Z. B. Gu, M. H. Lu, J. Wang, D. Wu, S. T. Zhang, X. K. Meng, Y. Y. Zhu, S. N. Zhu, Y. F. Chen and X. Q. Pan, "Structure, Optical, and Magnetic Properties of Sputtered Manganese and Nitrogen-Codoped ZnO Films," Applied Physics Letters, Vol. 88, No. 8, 2006, Article ID: 082111. $\underline{\text { doi: } 10.1063 / 1.2178466}$ 